\title{
Pore-size engineered nanoporous silica for efficient adsorption cooling and desalination cycle
}

\author{
Ramy H. Mohammed (iD ${ }^{1 凶}$, Emanne Rashad ${ }^{2}$, Ruiqing Huo ${ }^{3}$, Ming Su ${ }^{3}$ and Louis C. Chow ${ }^{4}$
}

Adsorption cooling and desalination (ACD) system powered by renewable energy has been considered as a promising solution to solve interconnected global problems such as freshwater scarcity, high-cost air conditioning, $\mathrm{CO}_{2}$ emission, and global warming. In this work, a new nanoporous silica was synthesized through a self-assembly process using a combination of ionic and non-ionic surfactants. The silica has shown unique pore structures, including high surface area and large pore volume, as well as ideal pore size distribution. The new silica was deposited (coated) over the ligaments of aluminum foam for use as a sorption bed. An uncoated aluminum foam packed with conventional silica RD (regular density) particles serves as a baseline sorption bed. The freshwater production rate and cooling power produced using the two sorbents were compared. Silica RD outperforms the new silica for cooling while the new silica is far better for desalination application. Insights for such results are provided.

npj Clean Water (2021)4:38; https://doi.org/10.1038/s41545-021-00129-y

\section{INTRODUCTION}

The demands for freshwater and air conditioning are growing steadily worldwide; however, both freshwater and cooling power are not affordable or even available in many developing countries. The World Health Organization (WHO) has announced that onethird of the global population does not have access to safe drinking water ${ }^{1}$. In 2019, air conditioning units were responsible for 1 Gton of $\mathrm{CO}_{2}$ emissions and about $8.5 \%$ of total electricity consumption ${ }^{2}$. The freshwater scarcity and cooling power demand will exacerbate over time due to the continuous population growth worldwide. Electrically and thermally driven desalination plants have been around for many years to produce potable water from saline water. However, their high energy consumption is a main challenge ${ }^{3}$. Powering desalination systems by renewable energy is vital to safeguarding our environment. At the same time, the cooling power needed for human comfort in buildings faces two significant challenges: reducing energy consumption and using environmentally friendly refrigerants. Therefore, the research community is always looking for an eco-system to output clean water and cooling power together, aiming to address energy-water-environment nexus effectively.

Sorption-based cooling and desalination technologies have been proposed and developed over the last decades to improve energy efficiency in air conditioning and cooling systems and alleviate the freshwater shortage ${ }^{4,5}$. Such technologies have received much attention because they could be powered by renewable energy resources and use eco-friendly refrigerants ${ }^{6}$. The adsorption cooling and desalination (ACD) cycle relies on using nanoporous materials with high water vapor affinity. The basic adsorption cycle consists of an evaporator, a condenser, and a sorption heat exchanger (i.e., sorption bed) filled with a nanoporous adsorbent material ${ }^{7}$. The cycle looks like a traditional vapor compression refrigeration cycle, except a sorption bed is used instead of the mechanical compressor. So, it can be inferred that the sorption bed configuration and nanoporous material are the prime pillars affecting the adsorption system performance ${ }^{7,8}$.
In this direction, many sorption bed configurations and nanoporous materials have been suggested to enhance the system's performance.

Sorption material is a nanoporous material with a large pore volume and a large surface area, where gas is adsorbed through van der Waals forces ${ }^{9}$. Upon completion of the adsorption process, the adsorbed gases are desorbed (regenerated) using thermal energy. The ACD cycle is formed by alternating the adsorption and desorption process. The cooling power and the freshwater production rate of the cycle depend mainly on the change in uptake, which is defined as the mass of refrigerant adsorbed per unit mass of adsorbent during the adsorption process. The main considerations in selecting a suitable adsorbent and refrigerant (i.e., working pair) are the high affinity of the refrigerant towards the adsorbent (high adsorbent capacity), high thermochemical stability of the working pair, high thermal diffusivity of adsorbent material, high latent heat of vaporization for the refrigerant, and low $\operatorname{cost}^{10}$. For such reasons, water is considered as one of the most suitable refrigerants for the ACD cycle.

Conventional adsorbents such as silica gel and zeolite have been extensively employed in sorption cycles due to their ability to adsorb water vapor. The change in uptake during the adsorption cycle is less than $0.2 \mathrm{~kg} / \mathrm{kg}$ of adsorbent for conventional adsorbents ${ }^{10,11}$. This low uptake makes the performance of ACD relatively low. $\mathrm{Ng}$ et al. ${ }^{12}$ estimated that $8 \mathrm{~kg}$ of freshwater could be produced per $\mathrm{kg}$ of absorbent in a day using a 4-bed adsorption cycle. $\mathrm{Ng}$ et al. ${ }^{13}$ reported that the specific daily water production (SDWP) increases by about $20 \%$ (from 7.4 to $8.9 \mathrm{~kg} / \mathrm{kg}$ of adsorbent) using heat recovery between the evaporator and condenser. Thu et al. $^{14}$ used an encapsulated evaporatorcondenser unit for heat recovery and were able to increase the SDWP to $26 \mathrm{~kg} / \mathrm{kg}$, which is the highest value of SDWP reported in the literature using silica gel/water. Thu et al. ${ }^{15}$ presented an analysis for a 2-bed silica gel adsorption desalination cycle with evaporator/condenser heat recovery (HR). This HR mode allows heat exchange between condenser and evaporator; thus, the

\footnotetext{
${ }^{1}$ Department of Mechanical Power Engineering, Zagazig University, Zagazig, Egypt. ${ }^{2}$ Department of Environmental Sciences, Faculty of Science, Alexandria University, Alexandria, Egypt. ${ }^{3}$ Department of Chemical Engineering, Northeastern University, Boston, MA, USA. ${ }^{4}$ Department of Mechanical and Aerospace Engineering, University of Central Florida, Orlando, FL, USA. ${ }^{凶}$ email: rhamdy@zu.edu.eg
} 
system's overall performance increases. Experimental results showed that this system yields a daily potable water production of about $15 \mathrm{~kg} / \mathrm{kg}$ of silica gel. Youssef et al. ${ }^{16}$ presented numerical results for an adsorption cooling and desalination cycle using AQSOA-Z02 as the adsorbent. $15.4 \mathrm{~kg}$ of potable water was produced per $\mathrm{kg}$ of adsorbent per day. Cooling power of about $164 \mathrm{~W} / \mathrm{kg}$ was also delivered at $10^{\circ} \mathrm{C}$ evaporator temperature. AQSOA-Z02 was reported to be more suitable than silica gel when cooling power and freshwater are needed, because the change in uptake of AQSOA-Z02 is more than that of silica gel in the range of operating conditions investigated ${ }^{17}$.

To improve the productivity of the adsorption cycle, different adsorbents, other than silica gel and zeolite, have been developed. These adsorbents include composite adsorbents and metal-organic frameworks (MOFs). These efforts of developing new adsorbents aimed to engineer the pore size distribution, pore volume, and surface area to make the adsorbents more suitable for cooling and desalination purposes. For instance, Ali et al. ${ }^{18}$ used a bed containing salt hydrate copper sulfate in a silica gel adsorption cycle. The cycle performance was investigated numerically, and their calculations indicated that the system could output potable water of up to $9 \mathrm{~kg} / \mathrm{kg}$ per day. Chan et al. ${ }^{19}$ reported that the maximum adsorption capacity of zeolite $13 x$ increases by a factor of about 4 after it was soaked in $\mathrm{CaCl}_{2}$ solution for a day. Bai et al. ${ }^{20}$ developed a composite material made of multi-walled carbon nanotube, zeolite $13 \times$, and $\mathrm{CaCl}_{2}$ salt, and evaluated its performance numerically and experimentally for cooling and desalination purposes. The experimental results showed that their sorption system using this composite could output a cooling effect of $490 \mathrm{~W} /$ $\mathrm{kg}$ and a SDWP of $18 \mathrm{~kg} / \mathrm{kg}$ per day. Elsayed et al. ${ }^{21}$ synthesized a composite adsorbent of $\mathrm{CaCl}_{2}$ and $\mathrm{MIL}-101(\mathrm{Cr})$ for sorption cooling application. They reported that adding $\mathrm{CaCl}_{2}$ can enhance the adsorption uptake at low pressure. The specific cooling power (SCP) improves from 168 to $388 \mathrm{~W} / \mathrm{kg}$ of adsorbent using water as the refrigerant at the evaporator and regeneration temperatures of $10^{\circ} \mathrm{C}$ and $90^{\circ} \mathrm{C}$, respectively. Han and Chakraborty ${ }^{22}$ used UiO-66 $(\mathrm{Zr})$, which is a MOF, with amino $\left(-\mathrm{NH}_{2}\right)$ and hydroxyl $(-\mathrm{OH})$ functional groups to enhance water vapor adsorption. It was shown that the SCP rises from $360 \mathrm{~W} / \mathrm{kg}$ to $840 \mathrm{~W} / \mathrm{kg}$ and the SDWP boosts from 24 to $40 \mathrm{~kg} / \mathrm{kg}$ of adsorbent, because of the presence of these functional groups on the UiO-66 (Zr) MOF surface. Elsayed et al. ${ }^{23}$ studied the adsorption characteristics of aluminum fumarate MOF compared to silica gel and zeolite for sorption desalination application. Using a chilled water temperature of $15^{\circ} \mathrm{C}$, aluminum fumarate (Al-Fum MOF) was found to have higher performance than silica gel. The SDWP and SCP of the ACD cycle using aluminum fumarate were $4.6 \mathrm{~kg} / \mathrm{kg}$ and $136 \mathrm{~W} / \mathrm{kg}$, respectively. Silica gel produced a SDWP of $4 \mathrm{~kg} / \mathrm{kg}$ and a SCP of $91 \mathrm{~W} / \mathrm{kg}$. Youssef et al. ${ }^{24}$ used CPO-27Ni MOF as an adsorbent, and found that it could produce potable water of $6.8 \mathrm{~kg} / \mathrm{kg}$ daily while yielding a SCP of $200 \mathrm{~W} / \mathrm{kg}$ using 1 bed. Han and Chakraborty ${ }^{25}$ investigated the adsorption cooling cycle's performance using $\left(\mathrm{CH}_{3}\right)_{2}-\mathrm{MOF}-801 /$ water and MOF-801/water. It was reported that $\left(\mathrm{CH}_{3}\right)_{2}-\mathrm{MOF}-801$ could produce a SCP $40 \%$ higher than MOF-801 due to the presence of methyl-functional ligand in MOF-81, which increases the affinity of water vapor molecules towards the adsorbent during the adsorption process.

It can be concluded that different types of adsorbents and adsorption beds configurations have been suggested and tested for cooling and desalination applications. However, the cooling power and freshwater production rate of the sorption cycle are still low compared to other technologies, such as the vapor compression cycle and multieffect desalination cycle. Silica gel and zeolite have low cost, but their capacities for water vapor are low. MOF materials were proven to be promising for these applications. However, these porous materials are expensive compared to conventional adsorbents. Also, they are produced only in small quantities, and scale-up production is the main challenge, therefore obstructing the implementation of MOFs in a practical adsorption system. There is an insistent need to synthesize morphology-controlled nanomaterials at a relatively low cost. These nanoporous materials should have large surface area, large pore volume, and desired pore size distribution corresponding to the operating conditions of the adsorption system $^{26}$. For adsorption cooling applications where the relative pressure (which is the ratio between the vapor pressure $\left(P_{\mathrm{v}}\right)$ and the saturation pressure $\left(P_{\mathrm{s}}\right)$ corresponding to the adsorbent temperature) is between 0.15 and 0.2 , the pore size distribution should be narrow and center at around $2 \mathrm{~nm}$ for the capillary condensation to fill the adsorbent pores to achieve high cooling power. For adsorption desalination applications where the relative pressure could be more than 0.4 , the pore size distribution should also be narrow but center at around $2.5-3 \mathrm{~nm}$. These pore size values are calculated based on the corrected Kelvin equation for porous material ${ }^{27}$.

The originality of this work centers around the synthesis of an innovative, pore-size engineered nanoporous silica used as an adsorbent, and the evaluation of the performances of aluminum foam-based adsorption beds in an ACD cycle for adsorption cooling and desalination. We have made a new porous silica structure by using a mixture of ionic and non-ionic surfactants to optimize the pore size distribution, and to maximize the pore volume and surface area. This new silica is deposited (coated) on the ligaments of aluminum foam to form a sorption bed. Another similar piece of aluminum foam was packed with commercially available silica RD (regular density), and its performance in adsorption cooling and desalination was compared with the coated adsorption bed. The SDWP, SCP, and gained output ratio GOR, which is defined as the mass of freshwater produced multiplied by the latent heat of vaporization and divided by the heat added in the ACD cycle, were measured for both the coated and packed beds. Finally, a mathematical model was constructed to investigate the performances of the coated and packed sorption beds under different operating conditions in adsorption cooling and desalination cycle.

\section{RESULTS AND DISCUSSION}

In the following subsections, the surface characteristics (surface area, pore volume, and pore size distribution) of new silica and silica RD were measured using the $\mathrm{N}_{2}$ adsorption technique. The adsorption isotherm of water onto the newly developed silica was measured, fitted, and analyzed. Two adsorption beds were also tested: aluminum foam packed with silica RD and aluminum foam coated with the new silica. The SDWP, SCP, and GOR were measured for the two sorption beds at various operating conditions. These calculations aim to set a comparison between the performance of the two sorption beds.

\section{Surface characterization analysis for the new silica}

The adsorption process is mainly controlled by the surface area, pore size, pore size distribution, and pore volume of the adsorbent ${ }^{28}$. The surface area of the new silica was estimated using the $\mathrm{N}_{2}$ gas adsorption method at $77 \mathrm{~K}$. The surface area analysis was done using the multi-point Brunauer-Emmett-Teller (BET) method, and was found to be $929 \mathrm{~m}^{2} / \mathrm{g}$. This value is about $49.6 \%$ more than that of conventional silica RD (BET surface area of silica RD is $621 \mathrm{~m}^{2} / \mathrm{g}^{27}$ ). The higher specific surface area value indicates the advantage of using the Pluronic ${ }^{\circledR}$ P123 and DTAB surfactants together in the new silica preparation. Figure 1a shows the adsorption and desorption of $\mathrm{N}_{2}$ (i.e., adsorption isotherm) on the pore surfaces of silica RD and new silica at $77 \mathrm{~K}$. The adsorption isotherm of silica RD was found to be of Type I, indicating monolayer adsorption. The new silica follows Type IV isotherm with a hysteresis behavior, which is attributed to 


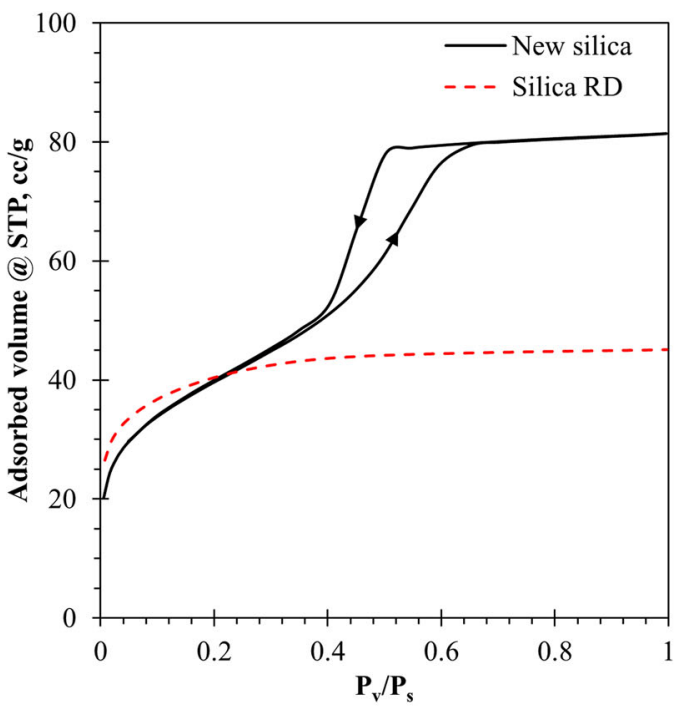

(a)

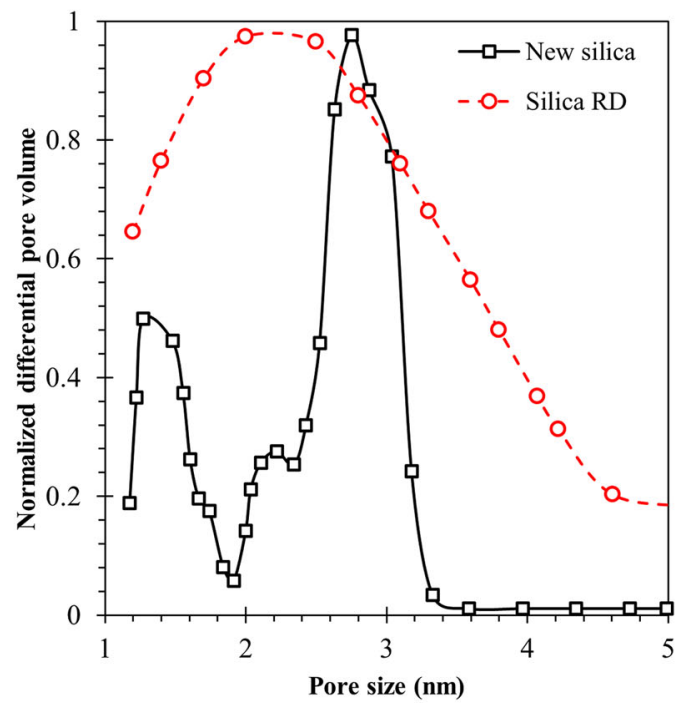

(b)

Fig. $1 \quad \mathbf{N}_{2}$ gas adsorption method. a $\mathrm{N}_{2}$ adsorption isotherm of the new silica and silica $\mathrm{RD}$ at $77 \mathrm{~K}$, and $\mathbf{b}$ the normalized pore size distributions of the two tested adsorbents, showing two peaks at around 1.27 (micropores) and $2.75 \mathrm{~nm}$ (mesopores) for the developed silica and wide distribution for silica RD.

adsorption/desorption behavior in adsorbent with capillary condensation. The pore size distributions of the two adsorbents were also measured, as depicted in Fig. 1b. While the normalized differential pore volume of silica RD has a broad pore size distribution, the new silica has two peaks at around 1.27 (micropores) and $2.75 \mathrm{~nm}$ (mesopores). The rather different pore size distribution in the new silica compared to the silica RD is due to the use the ionic and non-ionic surfactants. The narrow pore size distribution around $2.75 \mathrm{~nm}$ explains the sudden increase in the adsorption isotherm at a relative pressure of 0.4 , as shown in Fig. 1a. Thus, the adsorption mechanism in the new silica is surface layering followed by capillary condensation due to the presence of mesopores ${ }^{29}$. The pore volume of new silica was also estimated using the Density-Functional Theory (DFT) method ${ }^{30}$. It was found to be $0.773 \mathrm{~cm}^{3} / \mathrm{g}$ compared to $0.33 \mathrm{~cm}^{3} / \mathrm{g}$ for silica $\mathrm{RD}^{27}$. So, the pore volume of the new silica is larger than that of silica RD by a factor of 2.34. It can be inferred that using a mixture of ionic and non-ionic surfactants can produce a new nanoporous silica with high pore volume, and narrow pore size distribution favorable for adsorption desalination application.

\section{Silica/water isotherms measurement}

The adsorption isotherms of the two adsorbents were measured experimentally and plotted in Fig. 2. It was found that the maximum adsorption uptake of silica RD and new silica is 0.37 and $0.53 \mathrm{~kg} / \mathrm{kg}$ of adsorbent, respectively. The higher maximum adsorption uptake of the new silica is due to the higher pore volume, indicating the advantage of using two surfactants. The Dubinin-Astakhov (D-A) model was utilized to fit the adsorption isotherm of silica RD/water (Eq. (1)), while the adsorption isotherm of the developed silica/water was fitted using 4th order polynomial equation shown in Eq. (2). Regarding the new silica, its equilibrium uptake increases slightly as the relative pressure rises until 0.4 , beyond which a sudden increase in the adsorption uptake was observed because of the presence of capillary condensation. This behavior is due to the narrow pore size distribution around the pore diameter of $2.75 \mathrm{~nm}$, as plotted in Fig. $1 \mathrm{~b}$. On the other hand, the water adsorption uptake on silica $\mathrm{RD}$ increases steadily as the relative pressure increases, as presented in Fig. 2, due to the wide pore size distribution shown in Fig. $1 \mathrm{~b}$.

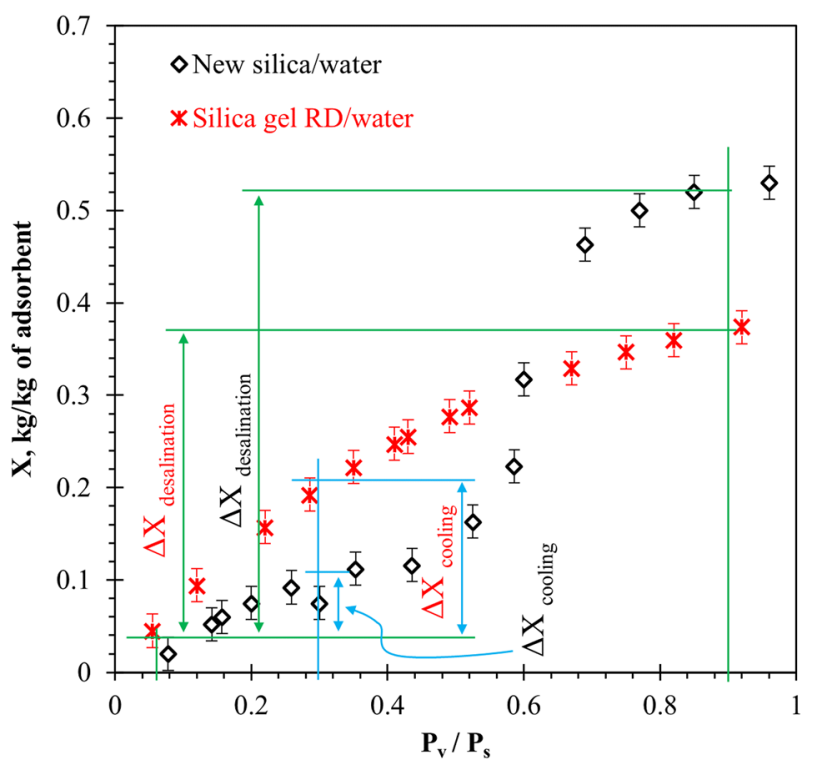

Fig. 2 Experimental water sorption isotherm of the two adsorbents with water. The adsorption isotherm of silica RD/water (red color) and developed silica/water (black color). The change in uptake of developed silica is much higher than that of silica RD for adsorption desalination applications. The opposite trend was observed for adsorption cooling applications.

In an adsorption desalination cycle, the relative pressure swings between 0.06 and 0.9 (see Fig. 2), resulting in a change in uptake across the cycle of about $0.32 \mathrm{~kg} / \mathrm{kg}$ when using silica RD and $0.48 \mathrm{~kg} / \mathrm{kg}$ when using the new silica (50\% higher). The higher change in the uptake of the new silica is due to its narrow pore size distribution around $2.75 \mathrm{~nm}$, allowing a sudden increase in the water uptake at a relative pressure between 0.4 and 0.7 . According to the Kelvin equation ${ }^{27}$, the water adsorption isotherm of the new silica is typically dominated by capillary condensation in this operating range. In an adsorption cooling cycle, the relative pressure changes from 0.06 to 0.3 during the adsorption process, allowing the change in uptake to be about $0.15 \mathrm{~kg} / \mathrm{kg}$ when using silica RD and about 
4

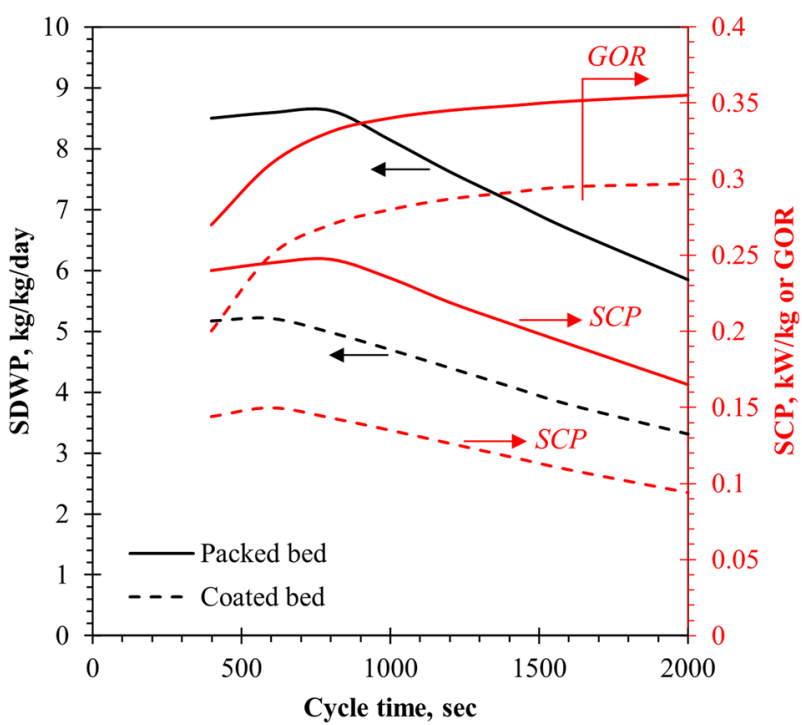

Fig. 3 SCP, SDWP, and GOR of the two sorption beds at different cycle times. SCP and SDWP of both adsorbents decline while GOP rise as the cycle time increases.

$0.08 \mathrm{~kg} / \mathrm{kg}$ when using the new silica (see Fig. 2). So, it can be concluded that the pore size distribution and pore volume for the new silica and silica RD favor desalination and cooling, respectively, as discussed later in detail.

Silica RD: $X=0.38 \exp \left(-0.502\left(-\ln \left(\frac{P_{\mathrm{v}}}{P_{\mathrm{s}}}\right)\right)^{1.36}\right) R^{2}=0.998$,

$$
\begin{aligned}
\text { New silica: } X= & -15.289\left(\frac{P_{\mathrm{v}}}{P_{\mathrm{s}}}\right)^{4}+27.662\left(\frac{P_{\mathrm{v}}}{P_{\mathrm{s}}}\right)^{3}-15.567\left(\frac{P_{\mathrm{v}}}{P_{\mathrm{s}}}\right)^{2} \\
& +3.4678 \frac{P_{\mathrm{v}}}{P_{\mathrm{s}}}-0.1844 R^{2}=0.984
\end{aligned}
$$

\section{System performance analysis}

This sub-section is devoted to investigating the influence of the cycle time, desorption temperature, and chilled fluid temperature (i.e., evaporator temperature) on the SCP, SDWP, and GOR of an ACD cycle using the packed silica RD bed or the coated new silica one. Figure 3 presents the influence of the cycle time (i.e., the adsorption and desorption period) on the SCP, SDWP, and GOR at a regeneration, cooling water, and chilled water temperature of $80^{\circ} \mathrm{C}, 25^{\circ} \mathrm{C}$, and $10^{\circ} \mathrm{C}$, respectively. It was found that the SCP of the packed silica RD bed is more than that of the coated new silica bed. This trend occurred because the change in uptake throughout the adsorption period is more in the case of packed bed (see Fig. 2). The SCP of both coated and packed bed first increases and reaches its maximum value at a cycle time of $600 \mathrm{~s}$ and $800 \mathrm{~s}$, respectively. The SCP decreases gradually for cycle times higher than the optimal values. For the packed bed, the SCP reduces from 0.247 to $0.165 \mathrm{~kW} / \mathrm{kg}$ when the cycle time changes from 800 to $2000 \mathrm{~s}$. With the coated silica, the SCP declines from 0.15 to $0.094 \mathrm{~kW} / \mathrm{kg}$ when the cycle time changes from 600 to $2000 \mathrm{~s}$.

The SDWP variation is like the SCP. This is because both are a function of the rate of change of water uptake. The packed silica $\mathrm{RD}$ bed produces a daily freshwater of $8.625 \mathrm{~kg} / \mathrm{kg}$ at an $800 \mathrm{~s}$ cycle time, while the coated new silica bed produces $5.214 \mathrm{~kg} / \mathrm{kg}$ of silica at a cycle time of $600 \mathrm{~s}$. Beyond the optimal cycle time, the water production rate of the packed and coated bed reduces to 5.85 and $3.31 \mathrm{~kg} / \mathrm{kg}$ of silica, respectively. This trend infers that the

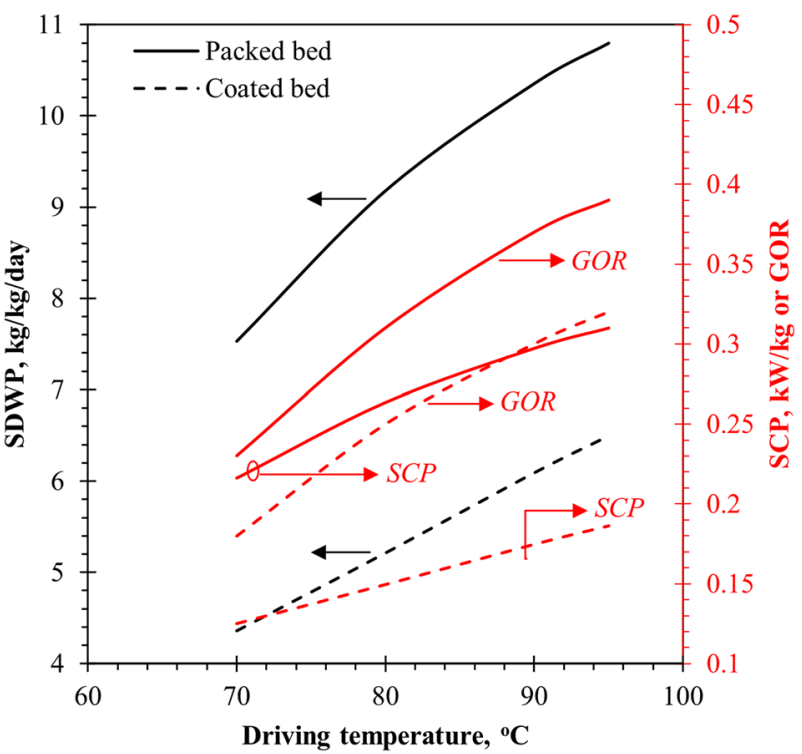

Fig. 4 SCP, SDWP, and GOR variations for the two beds at different driving temperatures. Regeneration temperature steadily increases SCP, SDWP, and GOR values of both adsorbents.

change in uptake after $300 \mathrm{~s}$ of adsorption time (i.e., half-cycle time) is negligible. The GOR values of ACD cycle using either the packed or coated bed are also shown in Fig. 3. It can be seen that the GOR of the packed bed is always higher than that of the coated silica bed, owing to the higher SDWP of the ACD cycle using the packed bed. The GOR of packed and coated bed is about 0.33 and 0.27 , respectively, at a cycle time of $800 \mathrm{~s}$. The GOR increases sharply at the shorter cycle times and then increases slowly after a cycle time of about $800 \mathrm{~s}$. This trend indicates that the reduction in the SDWP is less than the reduction in the rate of heat added throughout the adsorption process.

It can be inferred that the optimum cycle time for the packed and coated bed is $800 \mathrm{~s}$ and $600 \mathrm{~s}$, respectively. The SCP produced using the packed bed was about $0.245 \mathrm{~kW} / \mathrm{kg}$, which is nearly the same as what is produced at $800 \mathrm{~s}$. The same trends were observed for the SDWP values. Therefore, a cycle time of $600 \mathrm{~s}$ is considered in the following analyses.

Figure 4 depicts the change of the SCP, SDWP, and GOR at different driving (regeneration) temperatures. The SCP steadily increases as the regeneration temperature goes up for the packed and coated bed. This is attributed to the fact that the adsorbent uptake at the end of the regeneration process (which is equal to the uptake at the beginning of the adsorption process) decreases as the driving temperature increases. Therefore, the change in uptake increases with a higher driving temperature. The SCP reaches 0.31 and $0.186 \mathrm{~kW} / \mathrm{kg}$ using the packed and coated bed, respectively, at $95^{\circ} \mathrm{C}$ regeneration temperature. The change in uptake also affects the SDWP, as shown in Fig. 4. When a packed bed is used, the SDWP changes from 7.5 to $10.8 \mathrm{~kg} / \mathrm{kg}$ per day ( $44 \%$ increase) when the regeneration temperature changes from 70 to $95^{\circ} \mathrm{C}$. The GOR value also increases from 0.23 to 0.39 ( $70 \%$ increase), as presented in Fig. 4 . In turn, the SDWP of the coated bed increases from 4.4 to $6.5 \mathrm{~kg} / \mathrm{kg}$ per day $(\sim 48 \%$ increase), and the GOR rises from 0.18 to 0.32 ( 78\% improvement) as the regeneration temperature increases from 70 to $95^{\circ} \mathrm{C}$, respectively. The remarkable improvement in the SDWP and GOR indicates the considerable influence of the driving temperature on the ACD cycle outputs.

The results presented above indicate that the packed silica RD bed produces higher SCP, SDWP, and GOR than the coated silica bed. This preference is mainly because the operating conditions chosen are in the range, where the uptake change of silica RD 


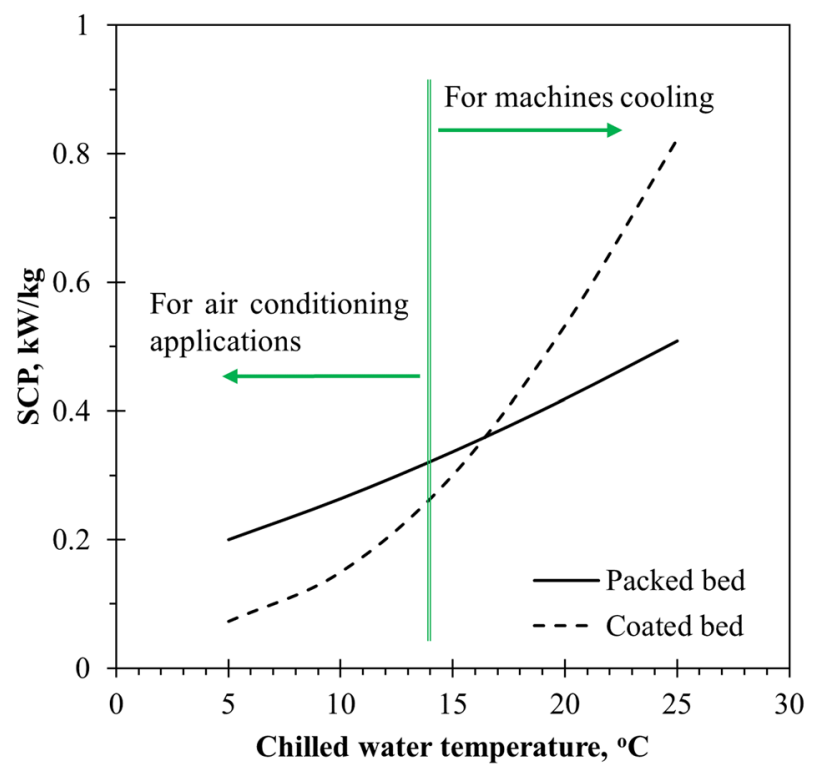

Fig. 5 SCP variations for the two beds at various chilled temperatures. The packed bed is favorable in air conditioning applications, while coated one is preferable in cooling machines.

throughout the adsorption process is more than that of the new silica (see Fig. 2). To take advantage of the sudden increase in the uptake of the new silica adsorbent, the chilled water temperature (i.e., evaporator temperature) is changed to raise the relative pressure at the end of the adsorption process. Figure 5 depicts the variation in SCP at different chilled water temperatures circulated in the evaporator. The SCP of the packed bed is found to be higher than that of the coated one when the chilled water temperature is less than $17^{\circ} \mathrm{C}$ (corresponding to a relative pressure of 0.62). Beyond this temperature, the coated bed outperforms the packed one, owing to its higher uptake for relative pressure higher than 0.6 (see Fig. 2). Using a chilled water temperature of $25^{\circ} \mathrm{C}$, the SCP of the packed bed is about $0.51 \mathrm{~kW} /$ $\mathrm{kg}$, while the coated new silica bed produces about $0.82 \mathrm{~kW} / \mathrm{kg}$ SCP ( 60\% higher). Producing cooling power at temperature less than $14{ }^{\circ} \mathrm{C}$ is suitable for air conditioning applications, while a temperature more than $14^{\circ} \mathrm{C}$ can be used for machines cooling like drilling, cutting, and milling.

Figure 6 presents the variations of SDWP and GOP as a function of chilled water temperature. Similar crossovers for the SDWP and GOR plots for the packed and coated beds can be observed at the chilled water temperature of about $17^{\circ} \mathrm{C}$. This is again due to the shape of the adsorption isotherms of the two adsorbents shown in Fig. 2. At a chilled water temperature of $25^{\circ} \mathrm{C}$, the SDWP is 28.7 and $17.7 \mathrm{~kg} / \mathrm{kg}$ per day for the coated and packed bed, respectively. For the coated silica bed, the GOR value increases from 0.2 to 0.78 ( $290 \%$ increase) as the chilled temperature changes from 5 to $25^{\circ} \mathrm{C}$. For the packed silica RD bed, the GOR value improves from 0.28 to $0.48(\sim 71 \%$ increase) when the chilled temperature changes from 5 to $25^{\circ} \mathrm{C}$.

It is clear that the ACD cycle performs much better when the new silica is used compared to when the traditional silica RD is used, when the evaporator temperature approaches the condenser temperature. This situation can be attained when a heat recovery (HR) loop between the evaporator and condenser is used $^{4,5}$. In this scenario, the heat rejected in the condenser (i.e., latent heat of condensation) is recovered in the evaporator. Therefore, this arrangement does not produce cooling power as a useful output, and it is used mainly for water desalination purpose. This configuration was studied further to examine the impact of the cycle time and regeneration temperature when the HR loop is

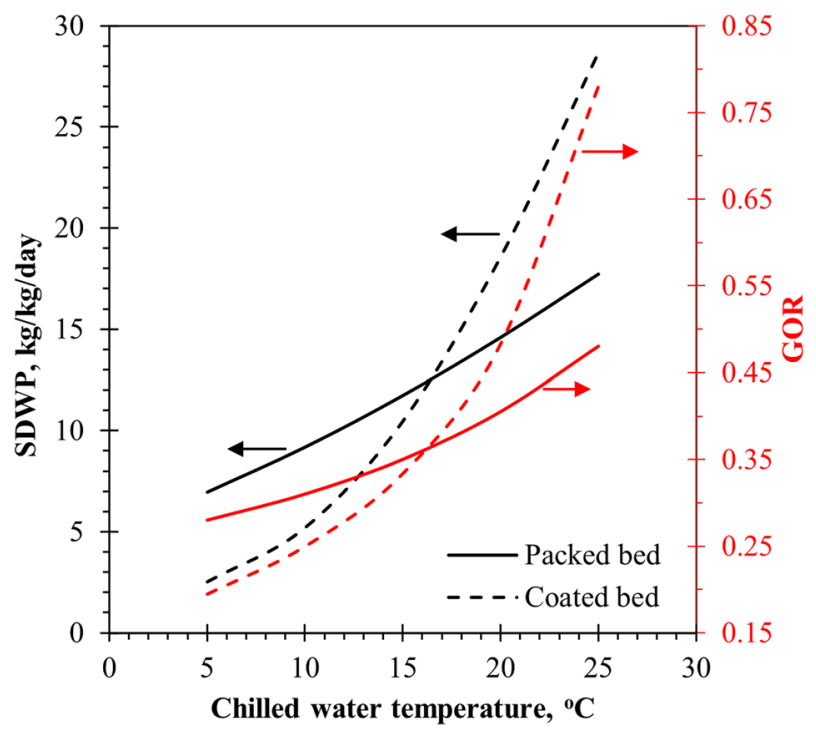

Fig. 6 SDWP and GOR variations for the two beds at different chilled water temperatures. The packed bed outperforms the coated one in terms of SDWP and GOR regardless the chilled water temperature in the absence of evaporator/condenser heat recovery loop.

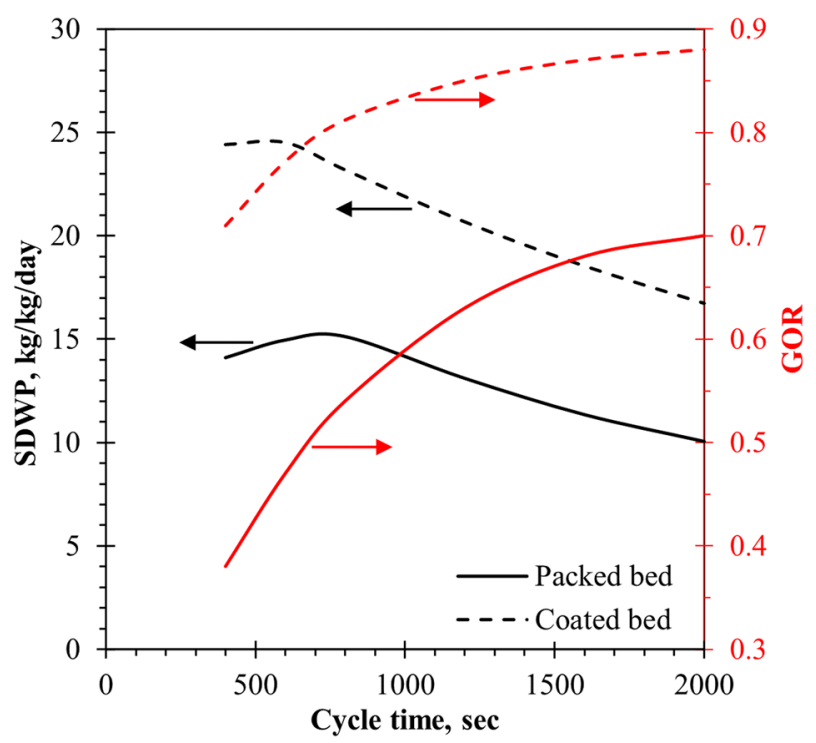

Fig. 7 SDWP and GOR delivered using the two sorption beds with HR at different cycle times. When cooling power is not required, a HR loop could be used to produce more freshwater at higher efficiency in the case of the coated bed.

employed. Figure 7 explores the effect of the cycle time on the SDWP and GOR values when a HR loop is used. It is found that the coated silica bed can produce a SDWP of about $24.5 \mathrm{~kg} / \mathrm{kg}$ every day at a GOR of 0.77 when the cycle time is $600 \mathrm{~s}$. The SDWP decreases monotonically when the cycle time changes from 600 to $2000 \mathrm{~s}$. The packed bed produces a maximum SDWP of $15.11 \mathrm{~kg} / \mathrm{kg}$ at a GOR of 0.54 and a cycle time of $800 \mathrm{~s}$. It should be noted that the SDWP when the new silica is used is about $62 \%$ higher than that when using the traditional silica RD.

Increasing the driving temperature leads to a remarkable increase in the SDWP and GOR of packed and coated bed, as shown in Fig. 8. When the new silica is used in the ACD cycle, the SDWP increases from 23.8 to $25.6 \mathrm{~kg} / \mathrm{kg}$ when the driving temperature changed from 65 to $95^{\circ} \mathrm{C}$. The same trend is also 
6

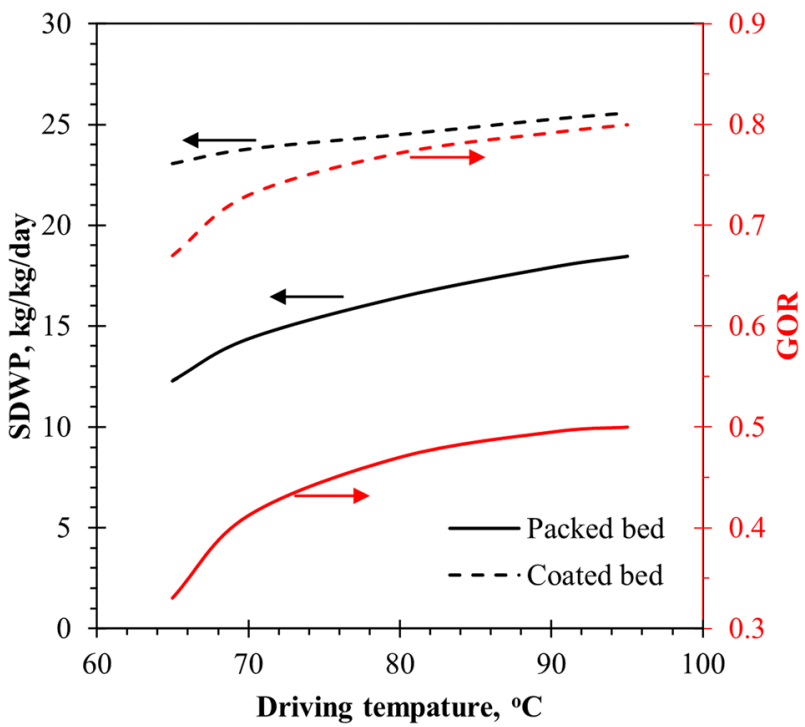

Fig. 8 SDWP and GOR variations for the two beds with HR at different driving temperatures. The SDWP and GOR values of the coated bed are higher than that of the packed one and steadily increases as the regeneration temperature increases.

observed for the packed silica RD bed. Interestingly, the ACD cycle using the new silica can be powered by a low-grade heat source with temperature as low as $65^{\circ} \mathrm{C}$ and produces a SDWP of $23 \mathrm{~kg} / \mathrm{kg}$ every day at a GOR value of 0.67 . These values are much better than those previously reported in the literature. Therefore, it can be concluded that the new silica adsorbent is a promising nanoporous material for adsorption desalination applications.

The use of combined ionic and non-ionic surfactants enables the synthesis of a new silica with a large pore volume and high surface area, as well as unique pore size distribution with two narrow spikes, which is very different than the broad pore size distribution in traditional silica RD. The BET surface area of the new silica is higher than that of silica RD by about $50 \%$. Also, the pore volume was higher than that of silica RD by a factor of 2.34 . The experimental and numerical results indicated that the new silica is preferred when freshwater is desired, while the silica RD is more suitable when the cooling effect is required. For adsorption desalination application, the new silica can produce a SDWP and GOR of $25 \mathrm{~kg} / \mathrm{kg}$ per day and 0.77 , respectively, which are much higher than those attainable by silica RD. These high values of SDWP and GOR are due to the narrow and spiky pore size distribution at around $2.75 \mathrm{~nm}$, resulting in a sudden increase in the adsorption uptake at a relative pressure of 0.4 . This relative pressure value is within the operating range for the adsorption desalination cycle, allowing the change in water uptake to be large across the cycle. Although the mechanism of forming unique pore structures in the case of using both ionic and polymeric surfactants remains unknown, it is reasonable that the packing of two different sized pores would increase the porosity of the materials (larger surface area and pore volume) similar to that of packing spheres of two sizes, where smaller ones can fill in the space formed by larger ones. Further, there seems to be a spinodal decomposition effect, in which the use of two surfactants actually limits the range of micelles (pore size) when only one surfactant is used. The results presented in this work also indicated that the new silica adsorbent coated over aluminum foam ligaments is a promising candidate for the adsorption desalination cycle owing to its unique microstructure characteristics. Future works are planned to provide more insights on the fundamentals about the structure performance correlation.

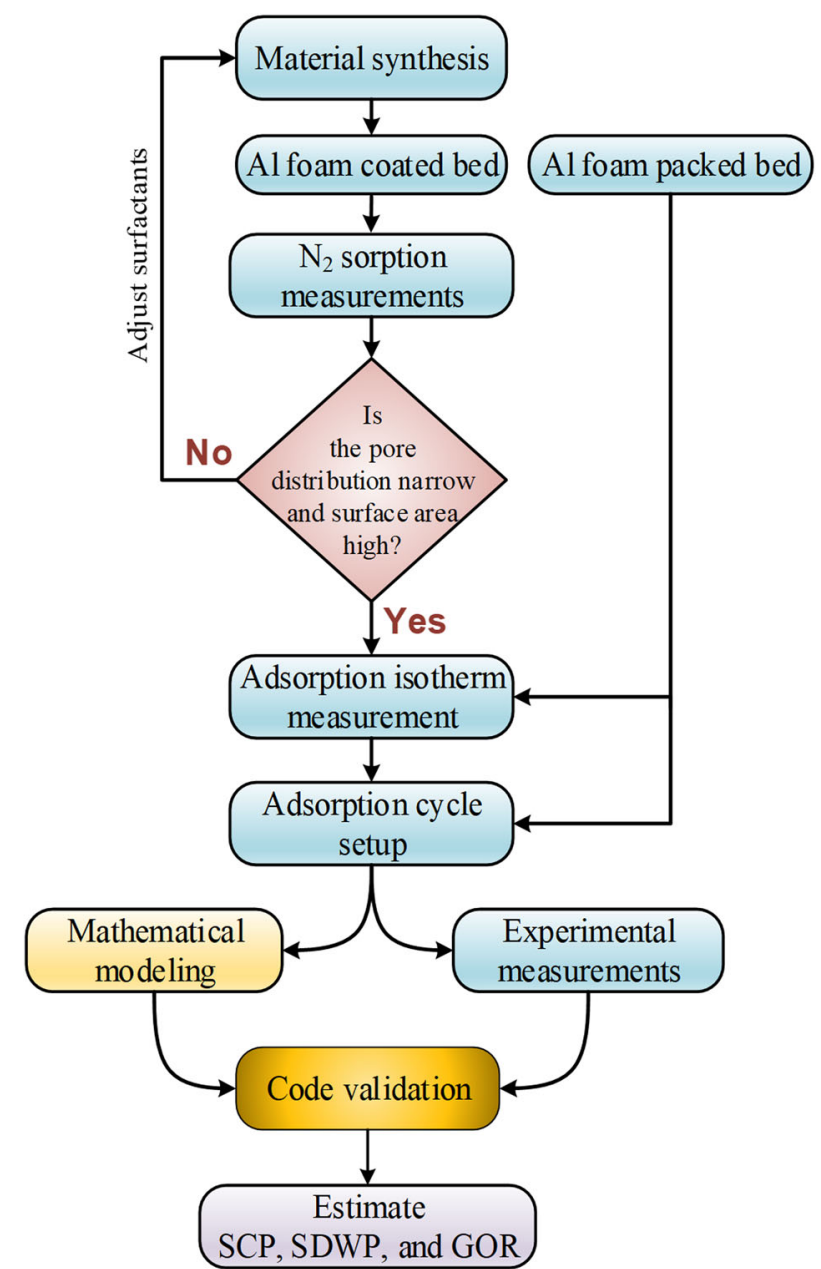

Fig. 9 Flowchart for the methodology of the present work. The surfactants used in the self-assembly process were adjusted to produce silica with desired microstructure characteristics for adsorption cooling and desalination applications.

\section{METHODS}

The present work included several activities, as visualized in Fig. 9. A new silica was synthesized and deposited/coated on the ligaments of an aluminum foam. The total pore volume, surface area, and pore size distribution were measured by performing nitrogen $\left(\mathrm{N}_{2}\right)$ adsorption/ desorption experiments on degassed silica at $77 \mathrm{~K}$. The coated aluminum foam served as a sorption bed for an ACD cycle. Another sorption bed was made using an uncoated aluminum foam packed with silica RD particles. Experiments were performed to evaluate the new silica and silica RD as an adsorbent in a sorption bed at the material and system level. At the material level, the adsorption isotherms and adsorption characteristics of the two adsorbents were measured. At the system level, the performances of the coated aluminum foam sorption bed and the packed aluminum foam sorption bed were evaluated experimentally at typical operating conditions of an ACD cycle. The SCP, SDWP, and GOR using the two sorption beds were measured and compared. A mathematical model was developed and validated against experimental measurements. The validated model was used to study the performance of both sorption beds in an ACD cycle under various operating conditions. The following sub-sections present the experimental and numerical works in detail.

\section{Fabrication of aluminum foam silica sorption beds}

Nanoporous silica was formed through a self-assembly process, in which silica was assembled by surfactants to form an ordered structure. The rich chemistry of surfactant molecules such as chemical nature, chain length, and branch structures allows tuning of pore size distribution, pore volume, and surface area of the nanoporous silica. It is known that the use of ionic surfactants yields microporous silica (pore size less than $2 \mathrm{~nm}$ ), while the 


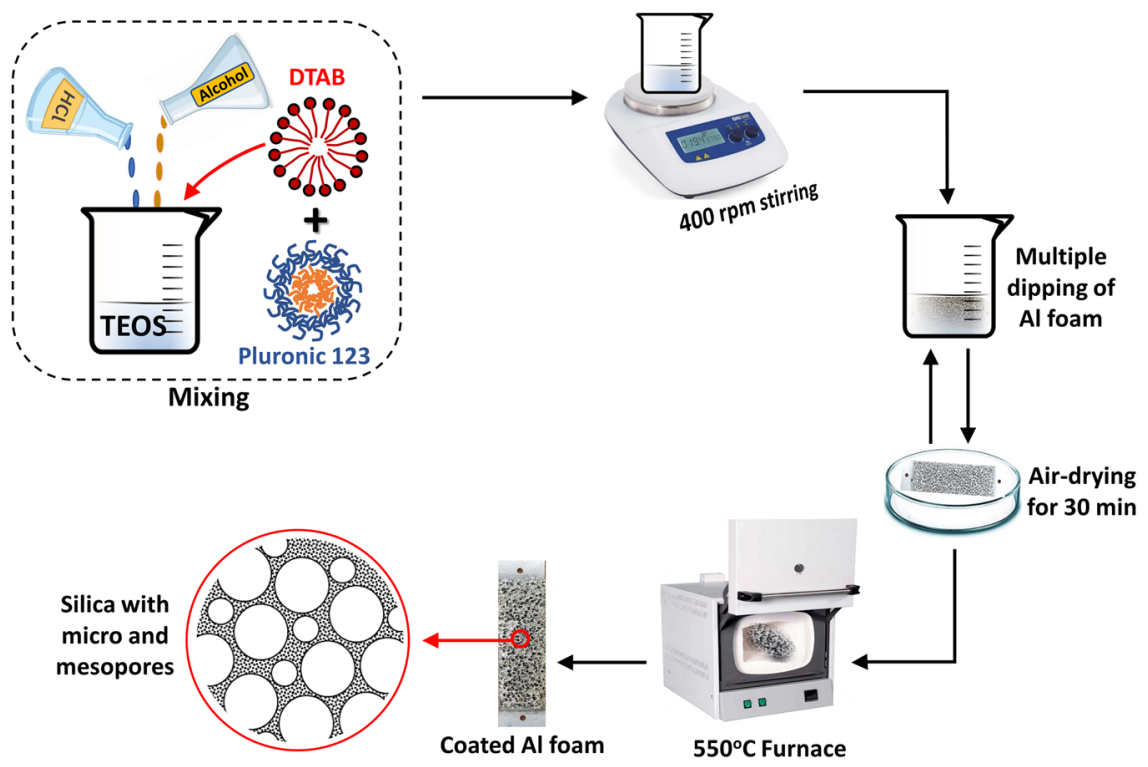

Fig. 10 Synthesis procedure of the Al foam coated sorption bed. Steps followed for preparing the developed, tuned silica and coating aluminum foam.

use of non-ionic surfactants yields mesoporous silica (pore size $\sim 2-20 \mathrm{~nm})^{31}$. However, it is not known whether ionic and non-ionic surfactants could be combined to synthesize silica with micro and mesopores to best suit water adsorption for desalination needs. In the present work, a symmetric non-ionic triblock copolymer surfactant (Pluronic ${ }^{\circledR}$ P123), comprising polyethylene glycol (PEO) and polypropylene glycol (PPO) in an alternating linear fashion (PEO-PPO-PEO), and an ionic surfactant dodecyl trimethylammonium bromide (DTAB) were used simultaneously. A silica solution was prepared by mixing Pluronic ${ }^{\circledR}$ P123 $(2 \mathrm{mmol})$ and DTAB $(20 \mathrm{mmol})$ with reagent alcohol $95 \%(80 \mathrm{ml})$, hydrochloric acid $(10 \mathrm{mmol})$, and tetraethyl orthosilicate TEOS $(0.2 \mathrm{~mol})$. The mixture was then stirred at $400 \mathrm{rpm}$ for $1 \mathrm{~h}$ to form a silica solution, as shown in Fig. 10.

To test the newly developed silica adsorbent for ACD applications, a high-porosity aluminum foam was coated using the newly developed silica solution. ERG Aerospace company produces an aluminum foam with ten pores per inch ( $90 \%$ porosity) and $5.8 \mathrm{~W} / \mathrm{m} . \mathrm{K}$ thermal conductivity (http:// ergaerospace.com/materials/duocel-aluminum-foam/). This foam was brazed to a flat-plate heat exchanger in which water was employed as a cooling/heating fluid during the adsorption/desorption process. The coated sorption bed was made by dipping the aluminum foam several times into the silica solution. The foam was dipped for $5 \mathrm{~s}$ in this solution and then air-dried for $0.5 \mathrm{~h}$. The process of dipping, followed by air-drying was repeated multiple times to increase the thickness of silica deposited on the ligaments of the aluminum foam. Finally, the aluminum foam was heated for $10 \mathrm{~h}$ at $550^{\circ} \mathrm{C}$ to form the coated sorption bed, as illustrated in Fig. 10. The coating thickness was measured to be about $0.5 \mathrm{~mm}$.

A second sorption bed was constructed by pouring silica RD particles, whose average diameter is $0.7 \mathrm{~mm}$, into the void space of a similar piece of uncoated aluminum foam voids. While filling the voids, the foam was shaken well to ensure the maximum amount of the silica RD particles got into the foam. The mass of the aluminum foam heat exchanger was measured before and after packing to estimate the mass of the silica RD particles resided in the foam. The step of packing and measuring the mass was repeated 3-4 times to ensure repeatability of the filling process.

\section{Experimental setup}

The experimental setup is shown in Fig. 11, and was described before in refs. ${ }^{26,32,33}$. It consisted of two vessels: one acted as an evaporator or a condenser, while the other one was the measuring vessel. The evaporator/ condenser vessel had water in which a copper coil was submerged. This vessel's temperature was controlled by a thermal bath that provided water at a specific temperature as needed. The measuring vessel was equipped with a load cell (with an accuracy of 1\%), where the sorption bed was placed. The experimental test rig has the flexibility of measuring the adsorption kinetics and isotherms of many adsorption working pairs,

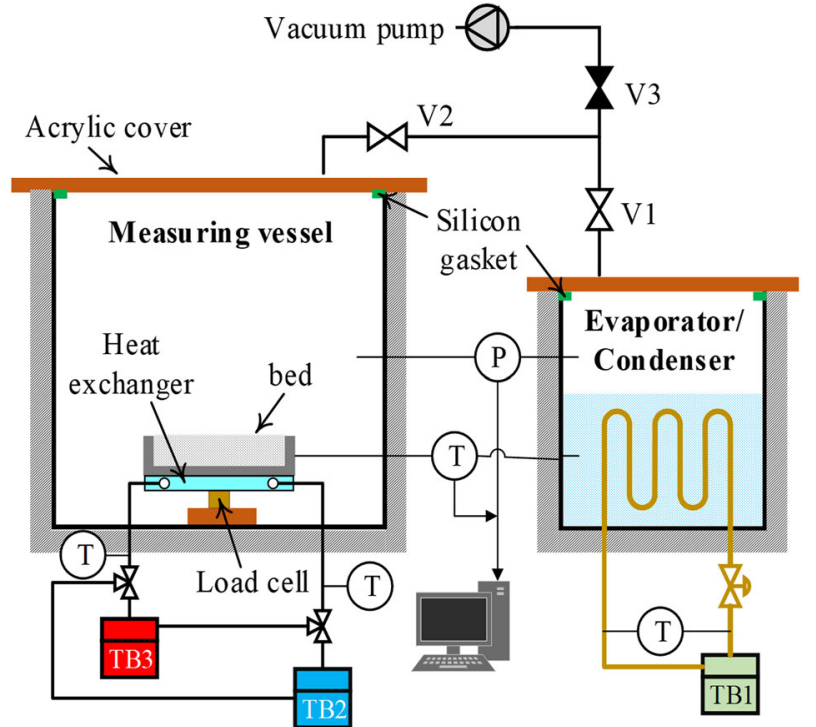

Fig. 11 Graphic description of the experimental setup. It was used to measure the adsorption isotherm and performance of the packed and coated beds.

including silica/water. It could also measure sorption bed performance under typical operating conditions of adsorption cooling and desalination systems. This is achieved by measuring the change in uptake using a load cell during the adsorption and desorption process. Moreover, the thermal response of the sorption bed is monitored by measuring its temporal temperature during testing using thermocouples (with an accuracy of $\pm 0.5^{\circ} \mathrm{C}$ ). The overall uncertainty in the readings of sensors was estimated ${ }^{34}$. The maximum errors of load cell, temperature, and pressure measurements were $1.5 \%, 2 \%$, and $1.5 \%$, respectively.

\section{Measurement of adsorption isotherms}

The sorption bed, either coated with the new silica or packed with silica RD particles, was placed on the load cell. The temperature of the sorption bed could be adjusted by means of a thermal bath, as displayed in Fig. 11. At the same time, the measuring vessel and evaporator vessel were disconnected from each other. The evaporator temperature was set at a specific temperature using another temperature bath. Before each isotherm measurement, the adsorbent was degassed at low pressure (less 
than $50 \mathrm{~Pa}$ ) and high temperature (about $90^{\circ} \mathrm{C}$ ). The adsorbent was presumed to be totally dry when the load cell reading remained constant for $2 \mathrm{~h}$. The adsorbent temperature was then reduced to the desired temperature at which adsorption uptake would be measured. The valves connecting the two chambers were then opened, allowing the water vapor at the evaporator temperature and pressure to enter the measuring vessel. The load cell response was recorded during this period, indicating the adsorption uptake. Equilibrium was attained when the load cell and thermocouples readings remained stable for $1 \mathrm{~h}$. The change in load cell readings through the adsorption period indicated the adsorption uptake at the specific bed temperature and evaporator pressure. This test was repeated many times at several temperatures and pressures to ensure the accuracy and repeatability of the adsorption isotherm measurements.

\section{Measurement of adsorption cycle performance}

After setting the adsorption bed on the weight gauge and degassing it, the large temperature jump method was followed to measure the cooling power and freshwater production rate ${ }^{35}$. The bed temperature was adjusted at an initial temperature of the adsorption process using a thermal bath. The value of this temperature is a unique state estimated from the adsorption isotherm and the cycle operating conditions. The evaporator was connected to the measuring chamber, letting the adsorbent sucked in water vapor until the equilibrium was reached. Afterward, the water temperature circulated in the adsorption bed was changed to the adsorption temperature (cooling water temperature), which was lower than the initial temperature. Therefore, the adsorption bed temperature decreased, allowing the adsorbent to suck in more water vapor. During this period (adsorption process), the load cell response, pressure transducers readings, and thermocouples readings were recorded. The rise in the load cell reading indicated the mass of water vapor adsorbed and the energy removed (cooling) at the evaporator. Once the adsorption process ended, the condenser temperature was adjusted, and hot water was applied to regenerate the water vapor from the adsorbent (desorption process). During this period, the reduction in the load cell readings corresponded to the regenerated water vapor, which was the freshwater production when it condensed in the condenser. The amount of freshwater produced was calculated using either one of the following equations:

$\dot{m}_{\mathrm{wa}}=\frac{1}{t_{\mathrm{c}}} \int_{0}^{t_{\mathrm{c}}} \frac{d L C_{\mathrm{a}}}{d \mathrm{t}} d \mathrm{t} \quad$ and $\quad \dot{m}_{\mathrm{wd}}=\frac{1}{t_{\mathrm{c}}} \int_{0}^{t_{\mathrm{c}}} \frac{d L C_{\mathrm{d}}}{d \mathrm{t}} d \mathrm{t}$,

where $\dot{m}_{\text {wa }}$ is the amount of water vapor adsorbed by the sorption bed during the adsorption process, $\dot{m}_{\mathrm{wd}}$ is the amount of water vapor desorbed during the desorption process, $t_{c}$ is the cycle time, $d L C_{a}$ is the increase in the load cell response during the adsorption process and $d L C_{d}$ is the reduction in the load cell response during the desorption process.

The specific daily water production (SDWP) is defined as the daily freshwater produced from the system per unit mass of adsorbent. The gained output ratio (GOR) indicates the energy efficiency of the cycle. It is defined as the ratio between the condenser capacity, where the water vapor from the sorption bed condenses and the rate of heat supplied during the desorption process. They can be estimated $a s^{5}$ :

$\mathrm{SDWP}=3600 \times 24 \times \frac{\dot{m}_{\mathrm{wd}}}{m_{\mathrm{s}}}$,

$\mathrm{GOR}=\frac{\dot{m}_{\mathrm{wd}} h_{\mathrm{fg}}}{\dot{\mathrm{Q}}_{\mathrm{des}}}$,

$\dot{Q}_{\text {des }}=\frac{1}{t} \int_{0}^{t} \dot{m}_{\mathrm{hw}} c_{\mathrm{p}_{\mathrm{w}}}\left(T_{\mathrm{hw}, \text { in }}-T_{\mathrm{hw}, \text { out }}\right) d \mathrm{t}$,

where $m_{\mathrm{s}}$ is the mass of adsorbent, $h_{\mathrm{fg}}$ is the latent heat of vaporization, $\dot{Q}_{\text {des }}$ is the heating power used during the desorption process, $\dot{m}_{\mathrm{hw}}$ is the mass flow rate of hot water used for desorption process, and $T_{\mathrm{hw}}$ is the hot water temperature.

The specific cooling power (SCP) is the evaporator load (cooling power) per unit mass of adsorbent, which can be calculated $\mathrm{as}^{26}$ :

$\mathrm{SCP}=\frac{\dot{m}_{\mathrm{wa}} h_{\mathrm{fg}}}{m_{\mathrm{s}}}$.
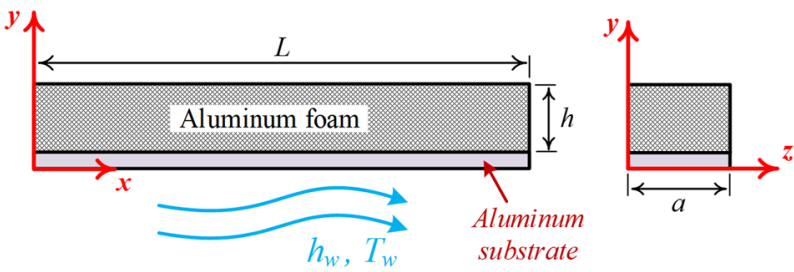

Fig. 12 Computational domain of aluminum foam coated or packed sorption bed. 3D domain used in the computational work.

\section{Mathematical model}

The 3D computational domain shown in Fig. 12 was adopted to examine the mass and heat transfer in the aluminum foam adsorption beds. It has a $2 \mathrm{~mm}$ aluminum substrate, which was brazed to the aluminum foam from one side, while the other one was exposed to a cooling/heating fluid throughout the adsorption/desorption period. The convective heat transfer coefficient was assumed as a boundary condition at this surface. The upper surface of the aluminum foam was exposed to water vapor coming from the evaporator over the adsorption period. So, a pressure boundary condition was assumed at this surface. The height and length of the aluminum foam are 10 and $120 \mathrm{~mm}$, respectively. Symmetry boundary conditions were set at all the other faces.

The following assumptions were considered to simplify the governing equations and to reduce the calculations time without sacrificing the solution accuracy. These assumptions are:

The overall thermal diffusivity of the investigated beds is spatially homogenous.

The bed porosity is homogenous.

The water vapor is treated as a perfect gas.

The solid and vapor phase are in thermal equilibrium.

The thermo-physical properties of the materials are not a function of temperature.

Using the above assumptions, governing equations were formulated to simulate the performances of both the packed and coated adsorption beds. They included the mass, momentum, and energy conservation equations. The mass conservation equation for the water vapor is written as:

$\varepsilon_{\mathrm{b}} \frac{\partial \rho_{\mathrm{v}}}{\partial t}+\nabla \cdot\left(\rho_{v} \vec{U}\right)=-\left(1-\varepsilon_{\mathrm{t}}\right) \rho_{\mathrm{s}} \frac{\partial X}{\partial t}$

where $\varepsilon_{b}$ is the bed porosity, which is 0.42 for the packed bed and 0.88 for the coated one $\mathrm{e}^{36}, \varepsilon_{\mathrm{t}}$ is the total bed porosity, which is 0.62 for the packed bed and 0.9 for the coated one ( Al foam porosity), and $X$ is the instantaneous water uptake which is predicted from the linear driving force (LDF) model, which is written as ${ }^{37}$ :

$\frac{\partial X}{\partial t}=\frac{60 D_{\mathrm{s}}}{d_{\mathrm{p}}^{2}}\left(X_{\mathrm{o}}-X\right)$,

$D_{\mathrm{s}}=2.54 \times 10^{-4} \exp \left(-\frac{5051.7}{T_{\mathrm{b}}}\right)$,

where $d_{\mathrm{p}}$ is the silica particle diameter for the packed bed or the coating thickness in the coated one (see Table 1) and $T_{\mathrm{b}}$ is the average bed temperature.

The momentum equation was solved to find the velocity and pressure profiles due to the intra-particle mass diffusion resistance effect. This equation is Darcy's equation and can be given $\mathrm{as}^{38}$ :

$\vec{U}=-\frac{K}{\mu} \nabla P$,

$K=\frac{d_{\mathrm{p}}^{2} \varepsilon_{\mathrm{b}}^{3}}{150\left(1-\varepsilon_{\mathrm{b}}\right)^{2}}$,

where $K$ is the permeability of the sorption bed $\left(\mathrm{m}^{2}\right)$.

The temperature profile of the sorption bed was calculated by solving the energy equation. The vapor phase and solid phase in each cell in the computational domain were assumed to be in thermal equilibrium. 
Table 1. Main parameters applied in the present work.

\begin{tabular}{llll}
\hline Parameter & Value & & Unit \\
\cline { 2 - 3 } & Packed bed & Coated bed & \\
\hline$d_{\mathrm{p}}$ & 0.7 & 0.5 & $\mathrm{~mm}$ \\
$\rho_{\mathrm{s}}$ & 2027 & 1200 & $\mathrm{~kg} / \mathrm{m}^{3}$ \\
$k_{\mathrm{s}}$ & 5.88 & 5.80 & $\mathrm{~W} / \mathrm{m} \mathrm{K}$ \\
$L \times a \times h$ & $12 \times 4 \times 1$ & & $\mathrm{~cm}$ \\
$C_{\mathrm{pv}}$ & 2.028 & & $\mathrm{~kJ} / \mathrm{kg} \mathrm{K}$ \\
$C_{\mathrm{pw}}$ & 4.186 & & $\mathrm{~kJ} / \mathrm{kg} \mathrm{K}$ \\
$C_{\mathrm{pfo}}$ & 0.9 & & $\mathrm{~kJ} / \mathrm{kg} \mathrm{K}$ \\
$C_{\mathrm{ps}}$ & 0.924 & & $\mathrm{~kJ} / \mathrm{kg} \mathrm{K}$ \\
$T_{\mathrm{c}}$ & 25 & & ${ }^{\circ} \mathrm{C}$ \\
$T_{\mathrm{e}}$ & 10 & & ${ }^{\circ} \mathrm{C}$ \\
$T_{\mathrm{d}}$ & 80 & & ${ }^{\circ} \mathrm{C}$ \\
$H_{\mathrm{a}}$ & 2415 & $\mathrm{~kJ} / \mathrm{kg}$ \\
$h_{\mathrm{w}}$ & 1800 & $\mathrm{~W} / \mathrm{m}^{2} \mathrm{~K}$ \\
\hline
\end{tabular}

Therefore, the energy equation can be formulated $\mathrm{as}^{7}$ :

$C_{\mathrm{t}} \frac{\partial T_{\mathrm{b}}}{\partial t}+\rho_{\mathrm{v}} C_{\mathrm{p}_{\mathrm{v}}} \vec{U} \cdot \nabla T_{\mathrm{b}}=\nabla \cdot\left(k_{\mathrm{b}} \nabla T_{\mathrm{b}}\right)+\left(1-\varepsilon_{\mathrm{t}}\right) \rho_{\mathrm{s}} H_{\mathrm{a}} \frac{\partial X}{\partial t}$,

$C_{\mathrm{t}}=\varepsilon_{\mathrm{b}} \rho_{\mathrm{v}} C_{\mathrm{p}_{\mathrm{v}}}+\rho_{\mathrm{fo}} C_{\mathrm{p}_{\mathrm{fo}}}+\left(1-\varepsilon_{\mathrm{t}}\right) \rho_{\mathrm{s}}\left(C_{\mathrm{p}_{\mathrm{s}}}+X C_{\mathrm{p}_{\mathrm{w}}}\right)$.

where $C_{\mathrm{t}}$ is the total specific heat capacity of the sorption bed $\left(\mathrm{J} / \mathrm{m}^{3} . \mathrm{K}\right), k_{\mathrm{b}}$ is the effective thermal conductivity of the bed $(\mathrm{W} / \mathrm{m} . \mathrm{K}), C_{p_{v}}$ is the vapor specific heat capacity (J/kg.K), $C_{p_{s}}$ is the specific heat capacity of adsorbent $(\mathrm{J} / \mathrm{kg} \mathrm{K}), C_{\mathrm{p}_{\mathrm{s}}}$ is the specific heat capacity of water $(\mathrm{J} / \mathrm{kg} \mathrm{K})$, and $\rho$ is the density $\left(\mathrm{kg} / \mathrm{m}^{3}\right)$.

The energy equation in the aluminum substrate attached to the aluminum foam was also considered in the numerical calculations ${ }^{39}$.

$\frac{\partial T_{\mathrm{al}}}{\partial t}=a_{\mathrm{al}} \nabla^{2} T_{\mathrm{al}}$

where $a_{\mathrm{al}}$ is the thermal diffusivity of the aluminum $\left(\mathrm{m}^{2} / \mathrm{s}\right)$.

The energy balance across the evaporator/condenser chamber is given $\mathrm{as}^{40}$ :

$\left(\mathrm{MC}_{\mathrm{p}}\right)_{\mathrm{e} / \mathrm{c}} \frac{d \mathrm{~T}_{\mathrm{e} / \mathrm{c}}}{d \mathrm{t}}=-m_{\mathrm{s}}\left(\frac{d \mathrm{X}}{d \mathrm{t}}\right) h_{\mathrm{fg}, T_{\mathrm{e} / \mathrm{c}}}-\dot{m}_{\mathrm{cw}} C_{\mathrm{p}_{\mathrm{w}}}\left(T_{\mathrm{cw}, \mathrm{o}}-T_{\mathrm{cw}, \mathrm{i}}\right)$,

where $M C_{p}$ is the heat capacity of the evaporator/condenser chamber $(\mathrm{J} / \mathrm{K})$.

The mass of water vapor adsorbed/desorbed during the adsorption/ desorption process, which is corresponding to the cooling power and freshwater produced, respectively, can be estimated as:

$\dot{m}_{\mathrm{wa}}=\left.\frac{m_{\mathrm{s}}}{t_{\mathrm{c}}} \int_{0}^{t_{\mathrm{c}}} \frac{\mathrm{d} X}{\mathrm{~d} t}\right|_{\mathrm{ads}} \mathrm{d} t$ and $\dot{m}_{\mathrm{wd}}=\left.\frac{m_{\mathrm{s}}}{t_{\mathrm{c}}} \int_{0}^{t_{c}} \frac{\mathrm{d} X}{\mathrm{~d} t}\right|_{\mathrm{des}} \mathrm{d} t$

Table 1 lists the operating parameters applied in the present study. During the parametric investigation, one parameter was altered while others remained constant.

Numerical results were compared with experimental measurements under the same operating conditions to check the validity of the present mathematical model. This comparison indicated that the experimental measurements and numerical results of average bed temperature deviate by about $2.6 \%$. This relatively small error pointed to the appropriateness of the present model in capturing the behavior of both sorption beds.

\section{DATA AVAILABILITY}

Raw datasets generated during the current study are available from the corresponding author on reasonable request.

Received: 11 February 2021; Accepted: 24 June 2021; Published online: 16 July 2021

\section{REFERENCES}

1. UNICEF \& WHO. WHO News Release https://www.who.int/news-room/detail/18 06-2019-1-in-3-people-globally-do-not-have-access-to-safe-drinking-waterunicef-who (2019).

2. lea. Cooling-Analysis_IEA https://www.iea.org/reports/cooling (2020).

3. Elbassoussi, M. H., Mohammed, R. H. \& Zubair, S. M. Thermoeconomic assessment of an adsorption cooling/desalination cycle coupled with a water-heated humidification-dehumidification desalination unit. Energy Convers. Manag. 223, 113270 (2020).

4. Ali, E. S., Mohammed, R. H. \& Askalany, A. A daily freshwater production of $50 \mathrm{m3} /$ ton of silica gel using an adsorption-ejector combination powered by low-grade heat. J. Clean. Prod. 282, 124494 (2021).

5. Askalany, A., Ali, E. S. \& Mohammed, R. H. A novel cycle for adsorption desalination system with two stages-ejector for higher water production and efficiency. Desalination 496, 114753 (2020).

6. Mohammed, R. H., Mesalhy, O., Elsayed, M. L. \& Chow, L. C. Novel compact bed design for adsorption cooling systems: Parametric numerical study. Int. J. Refrig. 80, 238-251 (2017).

7. Albaik, I., Al-Dadah, R., Mahmoud, S. \& Solmaz, İ. Non-equilibrium numerical modelling of finned tube heat exchanger for adsorption desalination/cooling system using segregated solution approach. Appl. Therm. Eng. 183, 116171 (2021).

8. Amirfakhraei, A., Zarei, T. \& Khorshidi, J. Performance improvement of adsorption desalination system by applying mass and heat recovery processes. Therm. Sci. Eng. Prog. 18, 100516 (2020).

9. Duong, X. Q. et al. Effect of coating thickness, binder and cycle time in adsorption cooling applications. Appl. Therm. Eng. 184, 116265 (2021).

10. Mohammed, R. H. \& Askalany, A. A. Green Energy and Technology 325-357 (Springer, 2019).

11. Alsaman, A. S., Askalany, A. A., Harby, K. \& Ahmed, M. S. A state of the art of hybrid adsorption desalination-cooling systems. Renew. Sustain. Energy Rev. 58, 692-703 (2016).

12. Ng, K. C., Thu, K., Saha, B. B. \& Chakraborty, A. Study on a waste heat-driven adsorption cooling cum desalination cycle. Int. J. Refrig. 35, 685-693 (2012).

13. Ng, K. C., Thu, K., Kim, Y., Chakraborty, A. \& Amy, G. Adsorption desalination: an emerging low-cost thermal desalination method. Desalination 308, 161-179 (2013).

14. Thu, K. et al. Numerical simulation and performance investigation of an advanced adsorption desalination cycle. Desalination 308, 209-218 (2013).

15. Thu, K., Yanagi, H., Saha, B. B. \& Ng, K. C. Performance analysis of a lowtemperature waste heat-driven adsorption desalination prototype. Int. J. Heat Mass Transf. 65, 662-669 (2013).

16. Youssef, P. G., Mahmoud, S. M. \& AL-Dadah, R. K. Numerical simulation of combined adsorption desalination and cooling cycles with integrated evaporator/ condenser. Desalination 392, 14-24 (2016).

17. Youssef, P. G., Mahmoud, S. M. \& AL-Dadah, R. K. Performance analysis of four bed adsorption water desalination/refrigeration system, comparison of AQSOA-ZO2 to silica-gel. Desalination 375, 100-107 (2015).

18. Ali, E. S., Askalany, A. A. \& Zohir, A. E. Innovative employing of salt hydration with adsorption to enhance performance of desalination and heat transformation systems. Appl. Therm. Eng. 179, 115614 (2020).

19. Chan, K. C., Chao, C. Y. H., Sze-To, G. N. \& Hui, K. S. Performance predictions for a new zeolite $13 \mathrm{X} / \mathrm{CaCl} 2$ composite adsorbent for adsorption cooling systems. Int. J. Heat Mass Transf. 55, 3214-3224 (2012).

20. Bai, S., Ho, T. C., Ha, J., An, A. K. \& Tso, C. Y. Study of the salinity effects on the cooling and desalination performance of an adsorption cooling cum desalination system with a novel composite adsorbent. Appl. Therm. Eng. 181, 115879 (2020).

21. Elsayed, E., AL-Dadah, R., Mahmoud, S., Anderson, P. \& Elsayed, A. Adsorption cooling system employing novel MIL-101(Cr)/CaCl2 composites: numerical study. Int. J. Refrig. 107, 246-261 (2019).

22. Han, B. \& Chakraborty, A. Advanced cooling heat pump and desalination employing functional UiO-66 ( $\mathrm{Zr}$ ) metal-organic frameworks. Energy Convers. Manag. 213, 112825 (2020).

23. Elsayed, E., AL-Dadah, R., Mahmoud, S., Anderson, P. \& Elsayed, A. Experimental testing of aluminium fumarate MOF for adsorption desalination. Desalination 475, 114170 (2020)

24. Youssef, P. G., Dakkama, H., Mahmoud, S. M. \& AL-Dadah, R. K. Experimental investigation of adsorption water desalination/cooling system using $\mathrm{CPO}-27 \mathrm{Ni}$ MOF. Desalination 404, 192-199 (2017).

25. Han, B. \& Chakraborty, A. Adsorption characteristics of methyl-functional ligand MOF-801 and water systems: Adsorption chiller modelling and performances. Appl. Therm. Eng. 175, 115393 (2020).

26. Mohammed, R. H., Mesalhy, O., Elsayed, M. L., Su, M. \& C. Chow, L. Revisiting the adsorption equilibrium equations of silica-gel/water for adsorption cooling applications. Int. J. Refrig. 86, 40-47 (2018). 
27. Saliba, S. et al. Combined influence of pore size distribution and surface hydrophilicity on the water adsorption characteristics of micro- and mesoporous silica. Microporous Mesoporous Mater. 226, 221-228 (2016).

28. Ruthven, D. M. Molecular Sieves-Science and Technology vol. 7, 1-43 (Springer, 2008).

29. Sonwane, C. G. \& Bhatia, S. K. Adsorption in mesopores: a molecular-continuum model with application to MCM-41. Chem. Eng. Sci. 53, 3143-3156 (1998).

30. Sun, J., Furness, J. W. \& Zhang, Y. Density functional theory. Math. Phys. Theor. Chem. https://doi.org/10.1016/B978-0-12-813651-5.00004-8 (2018).

31. Mehmood, A., Ghafar, H., Yaqoob, S., Gohar, U. F. \& Ahmad, B. Mesoporous silica nanoparticles: a review. J. Dev. Drugs 06, 1000174 (2017).

32. Mohammed, R. H., Mesalhy, O., Elsayed, M. L. \& Chow, L. C. Performance enhancement of adsorption beds with silica-gel particles packed in aluminum foams. Int. J. Refrig. 104, 201-212 (2019).

33. Mohammed, R. H. Experimental and Numerical Investigation of a Novel Adsorption Bed Design for Cooling Applications. Ph.D dissertation 2019, University of Central Florida, USA.

34. Qasem, N. A. A. \& Zubair, S. M. Performance evaluation of a novel hybrid humidification-dehumidification (air-heated) system with an adsorption desalination system. Desalination 461, 37-54 (2019).

35. Graf, S., Lanzerath, F. \& Bardow, A. The IR-Large-Temperature-Jump method: determining heat and mass transfer coefficients for adsorptive heat transformers. Appl. Therm. Eng. 126, 630-642 (2017).

36. Mohammed, R. H. et al. Performance of desiccant heat exchangers with aluminum foam coated or packed with silica gel. Appl. Therm. Eng. 166, 114626 (2020).

37. Naeimi, A., Nowee, S. M. \& Akhlaghi Amiri, H. A. Numerical simulation and theoretical investigation of a multi-cycle dual-evaporator adsorption desalination and cooling system. Chem. Eng. Res. Des. 156, 402-413 (2020).

38. Mohammed, R. H., Mesalhy, O., Elsayed, M. L. \& Chow, L. C. Scaling analysis of heat and mass transfer processes in an adsorption packed bed. Int. J. Therm. Sci. 133 , 82-89 (2018).

39. Manila, M. R., Mitra, S. \& Dutta, P. Studies on dynamics of two-stage air cooled water/silica gel adsorption system. Appl. Therm. Eng. 178, 115552 (2020).

40. Mohammed, R. H., Mesalhy, O., Elsayed, M. L. \& Chow, L. C. Assessment of numerical models in the evaluation of adsorption cooling system performance. Int. J. Refrig. 99, 166-175 (2019).

\section{ACKNOWLEDGEMENTS}

This work was supported by National Science Foundation (NSF) through Grant Numbers 1602984 and 1603215, and the Egyptian Ministry of Research and Higher Education.

\section{AUTHOR CONTRIBUTIONS}

R.H.M. proposed the idea and concept, designed the experimental setup, developed the numerical model, interpreted the results, and wrote the original and revised manuscript. E.R. drafted the original manuscript, contributed to the results visualization, and polished the final version. R.H. synthesized and characterized the developed adsorbent material. M.S. contributed to the concept, developed adsorbent material synthesis, data analysis, and manuscript writing. L.C.C. contributed to the concept, data analysis, and manuscript writing, and provided his expert advice during revision. All authors contributed to the interpretation and discussion of results.

\section{COMPETING INTERESTS}

The authors declare no competing interests.

\section{ADDITIONAL INFORMATION}

Correspondence and requests for materials should be addressed to R.H.M.

Reprints and permission information is available at http://www.nature.com/ reprints

Publisher's note Springer Nature remains neutral with regard to jurisdictional claims in published maps and institutional affiliations.

(i) Open Access This article is licensed under a Creative Commons Attribution 4.0 International License, which permits use, sharing, adaptation, distribution and reproduction in any medium or format, as long as you give appropriate credit to the original author(s) and the source, provide a link to the Creative Commons license, and indicate if changes were made. The images or other third party material in this article are included in the article's Creative Commons license, unless indicated otherwise in a credit line to the material. If material is not included in the article's Creative Commons license and your intended use is not permitted by statutory regulation or exceeds the permitted use, you will need to obtain permission directly from the copyright holder. To view a copy of this license, visit http://creativecommons. org/licenses/by/4.0/.

(c) The Author(s) 2021 